\title{
The therapeutic effects of Rho-ROCK inhibitors on CNS disorders
}

\author{
Takekazu Kubo' \\ Atsushi Yamaguchi' \\ Nobuyoshi Iwata ${ }^{2}$ \\ Toshihide Yamashita ${ }^{1,3}$ \\ 'Department of Neurobiology, \\ Graduate School of Medicine, Chiba \\ University, I-8-I Inohana, Chuo-ku, \\ Chiba 260-8670, Japan; ${ }^{2}$ Information \\ Institute for Medical Research \\ Ltd.; ${ }^{3}$ Department of Molecular \\ Neuroscience, Graduate School \\ of Medicine, Osaka University 2-2 \\ Yamadaoka, Suita, Osaka 565-087I, \\ Japan
}

\begin{abstract}
Rho-kinase (ROCK) is a serine/threonine kinase and one of the major downstream effectors of the small GTPase Rho. The Rho-ROCK pathway is involved in many aspects of neuronal functions including neurite outgrowth and retraction. The Rho-ROCK pathway becomes an attractive target for the development of drugs for treating central nervous system (CNS) disorders, since it has been recently revealed that this pathway is closely related to the pathogenesis of several CNS disorders such as spinal cord injuries, stroke, and Alzheimer's disease (AD). In the adult CNS, injured axons regenerate poorly due to the presence of myelin-associated axonal growth inhibitors such as myelin-associated glycoprotein (MAG), Nogo, oligodendrocytemyelin glycoprotein (OMgp), and the recently identified repulsive guidance molecule (RGM). The effects of these inhibitors are reversed by blockade of the Rho-ROCK pathway in vitro, and the inhibition of this pathway promotes axonal regeneration and functional recovery in the injured CNS in vivo. In addition, the therapeutic effects of the Rho-ROCK inhibitors have been demonstrated in animal models of stroke. In this review, we summarize the involvement of the Rho-ROCK pathway in CNS disorders such as spinal cord injuries, stroke, and AD and also discuss the potential of Rho-ROCK inhibitors in the treatment of human CNS disorders.
\end{abstract}

Keywords: neuron, Rho, Rho-kinase, axonal regeneration, central nervous system disorder

\section{Introduction}

The Rho family of small GTPases, including Rho, Rac, and Cdc42, has a central role in cellular motility and cytokinesis due to its involvement in the regulation of actin cytoskeletal dynamics (Fukata et al 2003; Riento and Ridley 2003; Narumiya and Yasuda 2006). As with other small GTPases, Rho functions as a molecular switch that controls various intracellular signaling pathways by shuttling between an active (GTP-bound) and inactive (GDP-bound) state. The exchange between the GTP- and GDP-bound forms is controlled by several regulatory proteins. Guanine nucleotide exchange factors (GEFs) enhance the conversion of a GDP-bound form to a GTP-bound form, which results in Rho activation. The GTP-bound form of Rho subsequently interacts with its specific downstream targets and triggers intracellular signalling cascades. On the contrary, GTPase activating proteins (GAPs) stimulate the GTPase activity of Rho, which leads to the conversion of an active GTP-bound form to an inactive GDP-bound form. Furthermore, guanine nucleotide dissociation inhibitors (GDIs) maintain Rho in an inactive GDP-bound form by sequestering it in the cytosol. One of the well-characterized downstream effectors of Rho is the Rho-associated, coiled-coil-containing protein kinase (ROCK) (Leung et al 1995; Ishizaki et al 1996; Matsui et al 1996). ROCK is a serine/threonine protein kinase with a molecular mass of $160 \mathrm{kDa}$. Two isoforms of ROCK exist, ie, ROCKI and ROCKII, and these show $65 \%$ similarity in their amino acid sequences and $92 \%$ identity in their kinase domains. The kinase domain of both ROCK isoforms is located at the amino terminus, and this is followed by a coiled-coil domain containing the Rho-binding site (RBD) and a 
pleckstrin-homology domain $(\mathrm{PH})$ with an internal cysteinerich domain (CRD) at the carboxyl terminus (Figure 1A) (Riento and Ridley 2003; Mueller et al 2005). The carboxyl terminal domain forms an autoinhibitory loop that folds back onto the catalytic domain and reduces the kinase activity of ROCK (Amano et al 1999). It has been suggested that the GTP-bound form of Rho activates ROCK by binding to the $\mathrm{RBD}$ in ROCK and counteracting the inhibitory interaction between the catalytic domain and the autoinhibitory region (Figure 1B).

With respect to tissue distribution, ROCKI and ROCKII transcripts are ubiquitously but differentially expressed (Nakagawa et al 1996). ROCKII is preferentially expressed in brain and muscle tissues, whereas ROCKI is abundantly expressed in nonneuronal tissues such as the liver, stomach, spleen, kidney, and testis. Both transcripts are highly expressed in the heart and lung. Although the two ROCK isoforms have been reported to have differential tissue distribution, the functional differences between them are less characterized. One such difference has been described in the process of membrane blebbing during apoptosis. In this case, it was demonstrated that caspase-3-dependent ROCKI cleavage removed the inhibitory domain of ROCKI, thereby rendering it constitutively active: this induced membrane blebbing during the course of apoptosis (Coleman et al 2001; Sebbagh et al 2001). Interestingly, ROCKII was not activated by caspase- 3 since it lacked the cleavage site. On the contrary, ROCKII, not ROCKI, was specifically truncated and activated by a proapoptotic protease granzyme B in a caspase-independent manner during the membrane blebbing process (Sebbagh et al 2005). Gene deletion of ROCKI or ROCKII in mice also demonstrated the functional differences between the 2 isoforms (Thumkeo et al 2003; Shimizu et al 2005). Most ROCKII-deficient mice show embryonic lethality probably due to a defect in the placenta with thrombosis, whereas failure of eyelid closure and closure of the ventral body wall has been reported in ROCKI-knockout mice. However, detailed analysis demonstrated that the latter phenotypic defects were also evident in ROCKII-knockout mice, suggesting that both isoforms share some aspects of the same
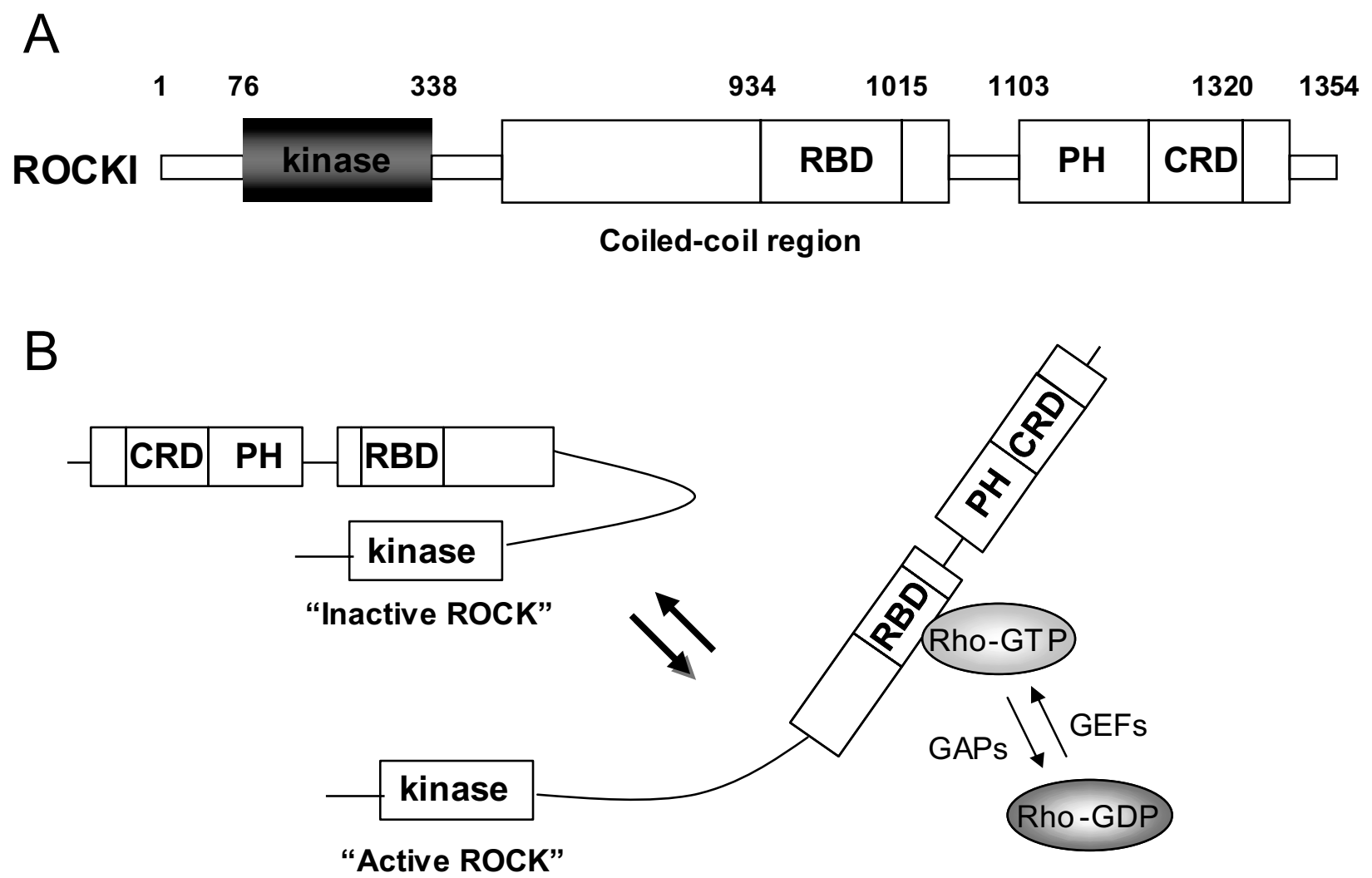

Figure I A schematic drawing of ROCKI and ROCK activation by Rho. (A) ROCKI has the kinase domain at the amino terminus, followed by a coiled-coil domain containing the Rho-binding site (RBD), and a pleckstrin-homology domain (PH) with an internal cysteine-rich domain (CRD). ROCKII has a very similar structure. (B) A proposed mechanism of ROCK activation by GTP-bound Rho is shown (Amano et al 1999). The carboxyl terminal domain forms an autoinhibitory loop that folds back onto the kinase domain and inhibits the kinase activity of ROCK. GTP-bound Rho binds to the RBD region in ROCK and renders the catalytic domain of ROCK to be accessible to its substrates, which results in the activation of ROCK. 
biological functions. It is noteworthy that after overcoming the perinatal problems, both ROCKI- and ROCKII-deficient mice develop normally without any obvious anatomical and functional abnormalities.

ROCK regulates the activities of many target proteins by its kinase activity. Some of these proteins such as the myosin light chain (MLC) regulate cell morphology (Brown and Bridgman 2004). Phosphorylated MLC induces actomyosin contraction by enhancement of myosin ATPase activity, which is a key step in cytoskeletal rearrangement (Ikebe and Hartshorne 1985; Ikebe et al 1986; Brown and Bridgman 2004). ROCK also increases MLC phosphorylation via the inhibition of MLC phosphatase by phosphorylation. Other ROCK substrates include the LIM (Lin11/Is11/Mec3) kinases (Ohashi et al 2000; Sumi et al 2001) and collapsin response mediator protein-2 (CRMP-2) (Arimura et al 2000, 2004), all of which are involved in the regulation of cytoskeletal reorganization.

Since a large number of reports have demonstrated the involvement of the Rho-ROCK pathway in the pathogenesis of several diseases, the Rho-ROCK pathway is considered to be a promising target for drug development in fields such as cardiovascular disease, cancer, erectile dysfunction, renal disease, and central nervous system (CNS) disorders (Cellek 2002; Shimokawa 2002; Lepley et al 2005; Mueller et al 2005; Nishikimi and Matsuoka 2006; Kubo et al 2007; Shimokawa and Rashid 2007). In this review, we summarize recent progress that has been made in understanding the involvement of the Rho-ROCK pathway in CNS disorders and discuss the potentials of Rho-ROCK inhibitors as pharmacotherapeutic drugs for treating CNS disorders.

\section{Spinal cord injury}

It is well known that in comparison to the axons of the peripheral nervous system (PNS), those of the adult mammalian CNS, including the spinal cord, regenerate poorly after injury. The lack of appropriate axonal regeneration in the CNS frequently results in permanent neuronal deficits such as paralysis following traumatic damage such as spinal cord injury. The pathology of CNS injuries, particularly spinal cord injuries, has been understood at a molecular level. It has been demonstrated that the lack of regeneration of injured CNS axons was mainly due to the CNS environment itself rather than due to any intrinsic disability of CNS nerve fibers (Richardson et al 1980; David and Aguayo 1981). At present, 3 axon outgrowth inhibitors in CNS myelin - Nogo, myelinassociated glycoprotein (MAG), and oligodendrocyte-myelin glycoprotein (OMgp) — have been well documented (Mueller et al 2005; Yamashita et al 2005; Kubo et al 2007). Nogo has 3 different isoforms, ie, NogoA, NogoB, and NogoC. NogoA is mainly expressed by CNS oligodendrocytes, whereas NogoB and NogoC are widely distributed outside the CNS. Nogo-66a, which is one of the inhibitory domains in the Nogo protein, is located in the $\mathrm{C}$-terminal region that is common to the 3 isoforms (Fournier et al 2001; Oertle et al 2003). $\mathrm{MAG}$, which is the first myelin-associated axon outgrowth inhibitor to be identified, is a transmembrane protein of the immunoglobulin superfamily and is distributed in both PNS and CNS myelin (McKerracher et al 1994; Mukhopadhyay et al 1994; Li et al 1996). OMgp, a glycosylphosphatidylinositol (GPI)-anchored 110-kDa glycoprotein, is located in oligodendrocytes and has an inhibitory effect on neurite outgrowth that is as potent as that of Nogo-66a (Kottis 2002; Wang 2002b). Interestingly, these 3 structurally distinct myelin-associated inhibitors bind to the same receptor, ie, $\mathrm{NgR}$, which is a GPI-anchored protein and is expressed in CNS neurons as well as in their axons (Josephson et al 2002; Wang 2002c). Since the GPI-linked NgR lacks an intracellular domain, it was assumed that a coreceptor that activates the intracellular signaling cascade was present. The low-affinity neurotrophin receptor $\mathrm{p} 75^{\mathrm{NTR}}$ has been identified as an $\mathrm{NgR}$ coreceptor. Initially, we reported that $\mathrm{p} 75^{\mathrm{NTR}}$ is required for neurite outgrowth inhibition by MAG by using postnatal dorsal root ganglion (DRG) neurons from mutant mice with a mutation in the $\mathrm{p} 75^{\mathrm{NTR}}$ gene (Yamashita et al 2002). Subsequently, it was found that $\mathrm{p} 75^{\mathrm{NTR}}$ and $\mathrm{NgR}$ form a receptor complex for MAG and the other 2 inhibitors, ie, Nogo and OMgp, suggesting that $\mathrm{p} 75^{\mathrm{NTR}}$ induces the intracellular inhibitory signals of all these myelin-associated proteins in association with $\mathrm{NgR}$ (Figure 2) (Wang et al 2002a; Wong et al 2002). Thereafter, Lingo-1 was identified as an additional component of the receptor complex with $\mathrm{NgR}$ and $\mathrm{p} 75^{\mathrm{NTR}}$ (Mi et al 2004). However, whether $\mathrm{NgR}$ is required for neurite outgrowth inhibition by the inhibitors is still debatable (Zheng et al 2005; Chivatakarn et al 2007). It has been recently demonstrated that $\mathrm{NgR} 1$ only mediates growth cone collapse, not neurite outgrowth inhibition, triggered by these inhibitors (Chivatakarn et al 2007). In contrast to $\mathrm{NgR}, \mathrm{p} 75^{\mathrm{NTR}}$ is involved in both growth cone collapse and neurite outgrowth inhibition induced by the inhibitors, suggesting that an unidentified receptor complex containing $\mathrm{p} 75^{\mathrm{NTR}}$ mediates neurite outgrowth inhibition triggered by the inhibitors (Figure 2) (Wang et al 2002a; Wong et al 2002; Yamashita et al 2002; Chivatakarn et al 2007). Further studies revealed that TROY (also known as TAJ), a member of the tumor necrosis factor (TNF) receptor family, 


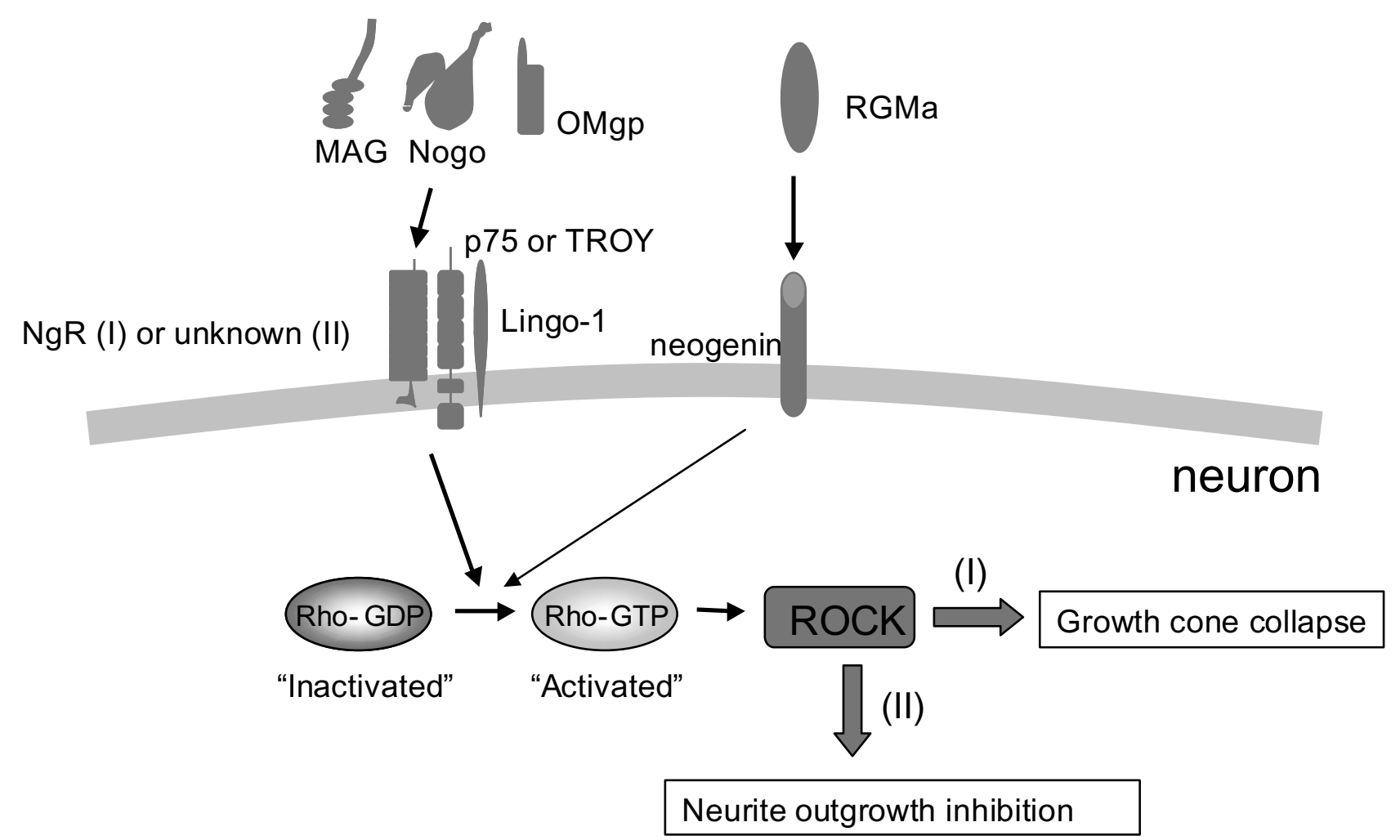

Figure 2 Intracellular signal cascades of myelin-associated neurite outgrowth inhibitors. Myelin-associated neurite outgrowth inhibitors such as Nogo, MAG, and OMgP bind to the same receptor, namely, $\mathrm{NgR}$. A receptor complex containing $\mathrm{P} 75^{\mathrm{NTR}}$ mediates the inhibitory signals such as growth cone collapse and neurite outgrowth inhibition via the activation of Rho and ROCK. NgR is reported to be only involved in the pathway resulting in growth cone collapse (I), but not in the pathway resulting in neurite outgrowth inhibition (II), which suggests that an unknown receptor for the neurite outgrowth inhibitors mediates the latter pathway (Chivatakarn et al 2007). In some neurons, TROY might be involved in this cascade instead of p $75^{\text {NTR }}$. RGMa binds to a different receptor, namely, neogenin and also activates the Rho-ROCK pathway. Other neurite outgrowth inhibitors such as chondroitin sulfate proteoglycans (CSPGs) and members of the semaphorin and ephrin families are also reported to activate the Rho-ROCK pathway for their inhibitory functions (not shown).

formed a functional receptor complex with $\mathrm{NgR}$ and Lingo-1, which mediates the inhibitory activity of myelin-associated inhibitors (Park et al 2005; Shao et al 2005). These suggest that several types of receptor complexes convey the inhibitory actions of myelin-associated inhibitors (Figure 2).

Nogo, MAG, and OMgp clearly inhibit neurite outgrowth in vitro; however, their involvement in axonal outgrowth inhibition following in vivo CNS injury remains debatable. Although blockade of the Nogo-NgR pathway by a neutralizing antibody (Schnell and Schwab 1990; Bregman et al 1995; Brosamle et al 2000; Merkler et al 2001) or its antagonistic peptide NEP1-40 (GrandPre et al 2002; $\mathrm{Li}$ and Strittmatter 2003) promoted axonal outgrowth and functional recovery in rats with spinal cord injury, Nogo- or NgR-deficient mice exhibited conflicting results (Kim et al 2003; Simonen et al 2003; Zheng et al 2003, 2005; Kim et al 2004; Dimou et al 2006). In addition, MAG-knockout mice or mice with the mutant $\mathrm{p} 75^{\mathrm{NTR}}$ gene did not exhibit better functional recovery and axonal regeneration after spinal cord injury (Bartsch et al 1995; Li et al 1996; Song et al 2004).
Recently, we discovered that the repulsive guidance molecule (RGMa) acts as another myelin-associated neurite outgrowth inhibitor that induces inhibitory signals independent of the NgR pathway (Figure 2) (Hata et al 2006; Yamashita et al 2007b). RGMa is a 33-kDa GPI-anchored protein, and neogenin has been found to be a functional receptor for RGM (Rajagopalan et al 2004; Yamashita et al 2007b). We found that RGMa significantly inhibits neurite outgrowth in cultured neurons (Hata et al 2006; Kubo et al in press). Interestingly, a neutralizing anti-RGMa antibody significantly enhances axonal outgrowth and functional recovery in rats with spinal cord injury (Hata et al 2006), suggesting that RGMa causes poor axonal regeneration and functional recovery after spinal cord injury in addition to other myelin-associated inhibitors.

Since there are several types of myelin-associated neurite outgrowth inhibitors, a strategy to block a common intracellular effector molecule(s), if any, would be more effective. Recent studies have revealed that these myelin-associated inhibitors trigger the axonal growth-inhibitory signals via 
the Rho-ROCK pathway (Figure 2) (Mueller et al 2005; Yamashita et al 2005; Kubo et al 2007). Botulinum toxin C3, which specifically inactivates Rho by enzymatic adenosine diphosphate (ADP)-ribosylation of the active site in Rho blocks neurite outgrowth inhibition by myelin and MAG (Lehmann et al 1999). Specific ROCK blockers such as Y-27632 counteract the inhibitory effects of these myelinassociated proteins on neurons (Dergham et al 2002; Fournier et al 2003; Hata et al 2006; Kubo et al in press). Rho activation by outgrowth inhibitors such as MAG and Nogo is mediated through $\mathrm{p} 75^{\mathrm{NTR}}$, which enhances the dissociation of the Rhoguanine nucleotide dissociation inhibitor (Rho-GDI) from RhoA after stimulation by the neurite outgrowth inhibitors (Yamashita and Tohyama 2003). Thereafter, RhoA activation is promoted by the Rho-guanine nucleotide exchange factor (Rho-GEF), which converts RhoA from an inactive GDP form to an active GTP form. In addition, a recent report demonstrated that intracellular proteolysis of $\mathrm{p} 75^{\mathrm{NTR}}$ is essential for both Rho activation and neurite outgrowth inhibition induced by MAG (Domeniconi et al 2005). Regarding the downstream effectors of the Rho-ROCK pathway, we recently reported that inactivation of CRMP-2 by ROCK-induced phosphorylation results in neurite outgrowth inhibition downstream of MAG (Mimura et al 2006). It has also been demonstrated that RhoA mediates the actions of myelin-associated neurite outgrowth inhibitors through direct binding to CRMP-4 (Alabed et al 2007). Furthermore, we found that RGMa inhibits neurite outgrowth through the activation of the RhoA-ROCK pathway in cultured neurons (Hata et al 2006; Kubo et al in press). In this case, the activation of myosin IIA, which is one of the downstream effectors of ROCK, is a key step for the exertion of the inhibitory effects of RGMa (Kubo et al in press). Most of the other documented neurite outgrowth inhibitors such as chondroitin sulfate proteoglycans (CSPGs) and members of the semaphorin and ephrin families are also reported to use the Rho-ROCK pathway for their inhibitory functions (Wahl et al 2000; Shamah et al 2001; Swiercz et al 2002; Monnier et al 2003; Lingor et al 2007). Therefore, Rho-ROCK is one of the most appropriate drug targets for counteracting the effects elicited by the different types of neurite outgrowth inhibitors.

In addition to Rho-ROCK, several other proteins have been identified as effectors of neurite outgrowth inhibitors, including conventional protein kinase C (PKC) (Hasegawa et al 2004; Sivasankaran et al 2004; Conrad et al 2007), glycogen synthase kinase (GSK)-3 (Eickholt et al 2002; Ito et al 2006), and the epidermal growth factor (EGF) receptor (Koprivica et al 2005). At least in vitro, multiple signals mediate the effects of the myelin-derived inhibitors.
After spinal cord injury, RhoA activation is detected in both the neurons and glial cells around the lesion site (Dubreuil et al 2003; Madura et al 2004), suggesting that activated Rho is involved in blocking CNS regeneration and providing a strategy to promote the regeneration of injured CNS axons by reversing this inhibitory pathway in vivo. The in vivo therapeutic effects of Rho inactivation were demonstrated following optic nerve injury. C3 transferase (C3) and its cell-permeable derivatives such as C3-05 and C3-07, which are specific Rho inhibitors, promote axonal regeneration after optic nerve injury (Lehmann et al 1999; Fischer et al 2004; Bertrand et al 2005). Subsequently, local application of $\mathrm{C} 3$ to the lesion site showed beneficial effects on histological and functional recovery in spinal cord transection injuries (Dergham et al 2002). ROCK inactivation also exerts therapeutic effects on CNS injury. In rodent spinal cord injury, fasudil, which is the only clinically available ROCK inhibitor, and Y-27632, another ROCK inhibitor, enhance axonal regrowth and functional recovery (Hara et al 2000; Dergham et al 2002; Fournier et al 2003; Sung et al 2003). We also found that the cytoplasmic ROCK inhibitory protein $\mathrm{p} 21^{\mathrm{Cip} 1 / \mathrm{WAF} 1}$ promoted the sprouting and regeneration of CST fibers and functional recovery in rat spinal cord hemisection injuries (Tanaka et al 2004). In addition, it was reported that Rho-ROCK inactivation exerts neuroprotective effects after spinal cord and optic nerve injuries and decreases tissue damage and cavity formation, which is another beneficial aspect of Rho-ROCK inhibition (Dubreuil et al 2003; Fischer et al 2004; Tanaka et al 2004; Bertrand et al 2005). These data in animal models strongly suggest that Rho-ROCK inhibitors provide therapeutic benefits in patients with spinal cord injury (Mueller et al 2005; McKerracher and Higuchi 2006; Kubo et al 2007).

\section{Stroke}

Ischemic stroke such as cerebral infarction is one of the primary CNS disorders and is associated with high morbidity and mortality. Animal models with permanent middle cerebral artery (MCA) occlusion demonstrated that infarction in the ischemic core occurs very rapidly after induction of ischemia and that ischemic damage expands to the peripheral region (ischemic penumbra) with time (Garcia et al 1993). Therefore, the main therapeutic target of ischemic stroke is the peripheral region. There is evidence to demonstrate that Rho-ROCK inhibition by C3; fasudil; hydroxyfasudil, which is an active metabolite of fasudil; and Y-27632 protects against ischemia-induced brain damage (Laufs et al 2000; Toshima et al 2000; Satoh et al 2001; Rikitake et al 2005). It has been suggested that the therapeutic effect is at least partly 
mediated by the upregulated expression of endothelial NO synthase by Rho-ROCK inhibition and the resultant increase in cerebral blood flow (Laufs et al 2000; Rikitake et al 2005). In addition, fasudil and hydroxyfasudil were reported to have a direct neuroprotective effect (Yamashita et al 2007a). It is noteworthy that delayed treatment with fasudil also prevents ischemia-induced neuronal death in the CA1 region of the gerbil hippocampus, suggesting that ROCK inhibition has a wide therapeutic time window in the treatment of ischemic stroke (Satoh et al 2007). Fasudil is currently the only clinically available ROCK inhibitor and was launched in Japan in1995 to treat cerebral vasospasm after subarachnoid hemorrhage (Shibuya et al 1992). Several groups have performed clinical trials of fasudil for patients with angina (Shimokawa et al 2002; Vicari et al 2005) or acute ischemic stroke (Shibuya et al 2005), and fasudil exerted significant therapeutic effects in both diseases. In the clinical trials for stroke, enrolled patients (160 patients) received fasudil within $48 \mathrm{~h}$ of ischemic stroke onset, and $60 \mathrm{mg}$ of fasudil was administered via intravenous injection twice daily for 14 days. Fasudil significantly improved both the neurological functions and clinical outcome of the patients and showed no severe side effects (Shibuya et al 2005). These results strongly suggest that Rho-ROCK inhibitors are beneficial and safe treatment options for ischemic stroke patients.

\section{Alzheimer's disease}

Alzheimer's disease (AD) is one of the most common causes of progressive dementia with massive neurodegeneration. The histopathological hallmarks of AD are extracellular deposits of senile plaques, which are composed of $\beta$-amyloid (A $\beta$ ) peptides, and intracellular neurofibrillary tangles composed of hyperphosphorylated tau proteins. A $\beta 1-40$ and the more amyloidogenic A $\beta$ 1-42 are produced by sequential proteolytic cleavage of the amyloid precursor protein (APP) by $\beta$ - and $\gamma$-secretase, whereas $\alpha$-secretase cleaves APP within the $\mathrm{A} \beta$ domain and produces no $\mathrm{A} \beta$ peptides (Hardy and Selkoe 2002; Walsh and Selkoe 2004). Results from studies on genetic mutations and neurotoxicity strongly suggest that $\mathrm{A} \beta$ peptides, particularly soluble oligomers of $\mathrm{A} \beta$ peptides, play key roles in the pathogenesis of AD (Walsh and Selkoe 2004; Venkitaramani et al 2007). Epidemiological studies demonstrated that the risk of $\mathrm{AD}$ development is reduced in users of some types of drugs such as nonsteroidal antiinflammatory drugs (NSAIDs) (McGeer et al 1990, 1996; Anthony et al 2000) and statins, which are cholesterollowering HMGCoA reductase inhibitors (Jick et al 2000; Wolozin et al 2000; Rockwood et al 2002; Yaffe et al 2002).
It was reported that some types of NSAIDs selectively reduce the production of amyloidogenic A $\beta 1-42$ both in vitro and in vivo, independent of their inhibitory effects on cyclooxygenase (COX) activity (Weggen et al 2001, 2003; Eriksen et al 2003; Sagi et al 2003; Takahashi et al 2003; Beher et al 2004; Kukar et al 2005). Among these compounds, R-flurbiprofen, which is an enantiomer of the classical racemic NSAID flurbiprofen, has reduced COX inhibitory activity and thus less toxicity (Morihara et al 2002; Eriksen et al 2003). R-Flurbiprofen lowered the levels of $A \beta 1-42$ and improved learning and memory deficits in a transgenic animal model of AD (Eriksen et al 2003; Kukar et al 2007). It also exerted beneficial effects in AD patients in a phase II clinical trial (Black et al 2006; Galasko et al 2007; Geerts 2007). It has been suggested that the inhibitory effects of NSAIDs on A $\beta$ 1-42 production are related to inhibition of the Rho-ROCK pathway both in cell cultures and in a transgenic mouse model of AD (Zhou et al 2003). However, many other groups have suggested that the decrease in $A \beta 1-42$ production by these NSAIDs is due to their direct inhibitory effects on $\gamma$-secretase rather than due to the inhibition of the Rho-ROCK pathway (Eriksen et al 2003; Takahashi et al 2003; Weggen et al 2003; Beher et al 2004; Kukar et al 2005; Leuchtenberger et al 2006). Statins are also reported to reduce $A \beta$ production in cell cultures and a transgenic mouse model of $\mathrm{AD}$ (Fassbender et al 2001; Petanceska et al 2002). The inhibition of $A \beta$ production by statins is mediated by both the cholesterol lowering-dependent and -independent mechanisms (Cole and Vassar 2006). Although the precise molecular mechanisms remain to be determined, the reduction of $A \beta$ by statins is at least partly attributed to the enhancement of $\alpha$-secretase activity (Kojro et al 2001; Parvathy et al 2004). Independent of the depletion of cellular cholesterol levels, statins inhibit small GTPases including Rho by lowering protein isoprenylation via the reduction of mevalonate synthesis (Cole and Vassar 2006). It has been suggested that the inhibition of Rho-ROCK by statins results in the activation of $\alpha$-secretase cleavage (Pedrini et al 2005) or the enhancement of APP lysosomal degradation (Ostrowski et al 2007), both of which lead to the inhibition of $A \beta$ production. In addition, it was recently reported that $A \beta$ inhibits neurite outgrowth through the activation of the Rho-ROCK pathway in SH-SY5Y neuroblastoma cells (Petratos et al 2008). It was suggested that the inhibitory effect of $A \beta$ is at least partly mediated by the induction of an alternatively spliced form of CRMP-2, ie, CRMP-2A, and the upregulated phosphorylation of CRMP-2 by ROCK. These data suggest that the Rho-ROCK pathway is involved not only in $A \beta$ production but also in $A \beta$-induced neurite outgrowth 
inhibition, suggesting that Rho-ROCK blockers would be beneficial in the treatment of $\mathrm{AD}$ patients.

\section{Development of Rho-ROCK inhibitors}

In the case of the Rho inhibitor, the cell-permeable $\mathrm{C} 3$ analog BA-210 was developed, and this molecule is currently in phase I/IIa clinical trials mainly to test its safety and tolerability in patients with acute thoracic or cervical spinal cord injuries without motor or sensory function (McKerracher and Higuchi 2006).

With regard to ROCK inhibitors, several types have been reported. Isoquinoline derivatives are typical ROCK inhibitors, and fasudil is one example (Figure 3) (Uehata et al 1997; Shimokawa 2002; Sasaki et al 2002). Fasudil blocks ROCK by competitive association with the ATP binding site of the kinase with a $\mathrm{K}_{\mathrm{i}}$ value of $0.4 \mu \mathrm{M}$ (Nagumo et al 2000; Jacobs et al 2006; Yamaguchi et al 2006a). Both ROCKI and ROCKII are inhibited by fasudil with $\mathrm{IC}_{50}$ values of $0.26 \mu \mathrm{M}$ and $0.32 \mu \mathrm{M}$, respectively (Shibuya et al 2005). Regarding the specificity, cAMP-dependent protein kinase (PKA) and protein kinase $\mathrm{C}$ are also inhibited by fasudil with $\mathrm{K}_{\mathrm{i}}$ values of
$1.0 \mu \mathrm{M}$ and $9.3 \mu \mathrm{M}$, respectively (Uehata et al 1997; Sasaki et al 2002). Hydroxyfasudil, a major active metabolite of fasudil in vivo, is slightly more effective than the original compound (Figure 3) (Rikitake et al 2005; Shibuya et al 2005). Dimethylfasudil (H-1152P) is an optimized derivative of fasudil, and it demonstrates higher potency and selectivity with $\mathrm{K}_{\mathrm{i}}$ values of $1.6 \mathrm{nM}$ for ROCK, $630 \mathrm{nM}$ for PKA, and $9.27 \mu \mathrm{M}$ for PKC (Sasaki et al 2002). More selective ROCK inhibitors in this category have also been developed by improvement of the fasudil and dimethylfasudil molecules (Tamura et al 2005). Y-27632, another type of ROCK inhibitor, is in the category of 4-aminopyridine derivatives (Uehata et al 1997). Y-27632 inhibits both ROCKI and ROCKII by competitively binding to the ATP binding pocket with $\mathrm{K}_{\mathrm{i}}$ values of $0.22 \mu \mathrm{M}$ and $0.3 \mu \mathrm{M}$, respectively (Ishizaki et al 2000; Jacobs et al 2006; Yamaguchi et al 2006b). With regard to its specificity, Y-27632 also inhibits citron kinase, PKN, PKC, and PKA with $\mathrm{K}_{\mathrm{i}}$ values of $5.3 \mu \mathrm{M}, 3.1 \mu \mathrm{M}, 73 \mu \mathrm{M}$, and $25 \mu \mathrm{M}$, respectively (Ishizaki et al 2000). Optimization of this series produces a more potent ROCK inhibitor, ie, Y-39983, which exerts therapeutic effects on the axonal regeneration of crushed optic nerves (Sagawa et al 2007) and reduction of<smiles>O=S(=O)(c1cccc2cnccc12)N1CCCNCC1</smiles>

fasudil<smiles>C[C@H](N)[C@H]1CC[C@H](C(=O)Nc2ccncc2)CC1</smiles>

Y-27632<smiles>O=S(=O)(c1ccccc1)N1CCCNCC1</smiles>

hydroxyfasudil

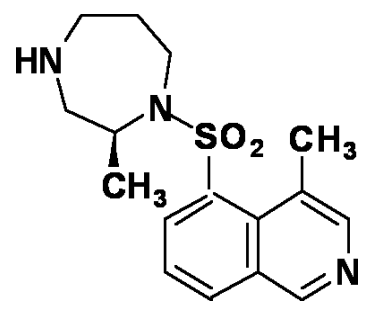

Dimethylfasudil (H-1152P)<smiles>C[C@H](N)c1ccc(C(=O)Nc2ccnc3[nH]ccc23)cc1</smiles>

Y-39983

Figure 3 The chemical structures of ROCK inhibitors. Two typical ROCK inhibitors, ie, fasudil and Y-27632, and their derivatives are shown. Isoquinoline derivatives, including fasudil, hydroxyfasudil, and dimethylfasudil, are represented on the upper side. 4-Aminopyridine derivatives such as Y-27632 and Y-39983 are shown on the lower side. 
intraocular pressure, which is beneficial in the treatment of glaucoma (Nakajima et al 2005; Tokushige et al 2007). Other types of ROCK inhibitors have also been described (Mueller et al 2005; Kubo et al 2007; Shimokawa and Rashid 2007).

\section{Safety issues}

Fasudil, the only clinically available ROCK inhibitor, can be used to predict the expected side effects of ROCK inhibitors in humans. ROCK inhibition by fasudil in patients with cerebral vasospasm does not cause any severe side effects (Shibuya et al 1992). Additionally, in clinical trials of fasudil, in which patients with stable effort angina or acute ischemic stroke were treated, fasudil was well tolerated with no severe side effects, including none on the blood pressure and heart rate (Shimokawa et al 2002; Shibuya et al 2005; Vicari et al 2005).

However, ROCKI- or ROCKII-knockout mice exhibited developmental abnormalities (Thumkeo et al 2003; Shimizu et al 2005), and the administration of Y-27632 to mouse embryos resulted in severe prenatal defects (Wei et al 2001). These data strongly indicate that ROCK has critical functions during the developmental stage. Interestingly, it was recently reported that ROCK inhibition by the intracerebroventricular administration of Y-27632 increases anxiety-related behavior in mouse emotional behavior tests (Saitoh et al 2006). In addition, long-term topical administration of high doses of Y-39983 to the eyes results in sporadic punctate subconjunctival hemorrhage in rabbit and monkey eyes (Tokushige et al 2007). Therefore, further evaluation is required to assess the safety of ROCK inhibitors.

\section{Concluding remarks}

In this review, we summarize the therapeutic effects of RhoROCK inhibitors in animal models of CNS disorders such as spinal cord injuries, stroke, and AD. Further, in stroke patients, ROCK inhibition by fasudil led to therapeutic effects without severe side effects. These data strongly suggest that Rho-ROCK inhibition is a promising strategy to overcome CNS disorders such as spinal cord injuries, stroke, and AD in humans.

\section{Disclosure}

The authors declare no conflicts of interest.

\section{References}

Alabed YZ, Pool M, Ong Tone S, et al. 2007. Identification of CRMP4 as a convergent regulator of axon outgrowth inhibition. $J$ Neurosci, 27:1702-11.

Amano M, Chihara K, Nakamura N, et al. 1999. The COOH terminus of Rho-kinase negatively regulates rho-kinase activity. $J$ Biol Chem, 274:32418-24.
Anthony JC, Breitner JC, Zandi PP, et al. 2000. Reduced prevalence of AD in users of NSAIDs and $\mathrm{H} 2$ receptor antagonists: the Cache County study. Neurology, 54:2066-71.

Arimura N, Inagaki N, Chihara K, et al. 2000. Phosphorylation of collapsin response mediator protein- 2 by Rho-kinase. Evidence for two separate signaling pathways for growth cone collapse. J Biol Chem, 275:23973-80.

Arimura N, Menager C, Fukata Y, et al. 2004. Role of CRMP-2 in neuronal polarity. J Neurobiol, 58:34-47.

Bartsch U, Bandtlow CE, Schnell L, et al. 1995. Lack of evidence that myelin-associated glycoprotein is a major inhibitor of axonal regeneration in the CNS. Neuron, 15:1375-81.

Beher D, Clarke EE, Wrigley JD, et al. 2004. Selected non-steroidal antiinflammatory drugs and their derivatives target gamma-secretase at a novel site. Evidence for an allosteric mechanism. J Biol Chem, 279:43419-26.

Bertrand J, Winton MJ, Rodriguez-Hernandez N, et al. 2005. Application of Rho antagonist to neuronal cell bodies promotes neurite growth in compartmented cultures and regeneration of retinal ganglion cell axons in the optic nerve of adult rats. J Neurosci, 25:1113-21.

Black S, Wilcock GK, Hawworth J, et al. 2006. Efficacy and safety of MPC-7869 (R-flurbiprofen), a selective Abeta42 lowering agent in mild Alzheimer's disease: results of a 12-month phase 2 trial and 1-year follow on study. Neurology, 66(suppl 2):A347.

Bregman BS, Kunkel-Bagden E, Schnell L, et al. 1995. Recovery from spinal cord injury mediated by antibodies to neurite growth inhibitors. Nature, 378:498-501.

Brosamle C, Huber AB, Fiedler M, et al. 2000. Regeneration of lesioned corticospinal tract fibers in the adult rat induced by a recombinant, humanized IN-1 antibody fragment. $J$ Neurosci, 20:8061-8.

Brown ME, Bridgman PC. 2004. Myosin function in nervous and sensory systems. J Neurobiol, 58:118-30.

Cellek S, Rees RW, Kalsi J. 2002. A Rho-kinase inhibitor, soluble guanylate cyclase activator and nitric oxide-releasing PDE5 inhibitor: novel approaches to erectile dysfunction. Expert Opin Investig Drugs, 11:1563-73.

Chivatakarn O, Kaneko S, He Z, et al. 2007. The Nogo-66 receptor NgR1 is required only for the acute growth cone-collapsing but not the chronic growth-inhibitory actions of myelin inhibitors. $J$ Neurosci, 27:7117-24.

Cole SL, Vassar R. 2006. Isoprenoids and Alzheimer's disease: a complex relationship. Neurobiol Dis, 22:209-22.

Coleman ML, Sahai EA, Yeo M et al. 2001. Membrane blebbing during apoptosis results from caspase-mediated activation of ROCK I. Nat Cell Biol, 3:339-45.

Conrad S, Genth H, Hofmann F, et al. 2007. Neogenin-RGMa signaling at the growth cone is bone morphogenetic protein-independent and involves RhoA, ROCK, and PKC. J Biol Chem, 282:16423-33.

David S, Aguayo AJ. 1981. Axonal elongation into peripheral nervous system "bridges" after central nervous system injury in adult rats. Science, 214:931-3.

Dergham P, Ellezam B, Essagian C, et al. 2002. Rho signaling pathway targeted to promote spinal cord repair. $J$ Neurosci, 22:6570-7.

Dimou L, Schnell L, Montani L, et al. 2006. Nogo-A-deficient mice reveal strain-dependent differences in axonal regeneration. $J$ Neurosci, 26:5591-603.

Domeniconi M, Zampieri N, Spencer T, et al. 2005. MAG induces regulated intramembrane proteolysis of the p75 neurotrophin receptor to inhibit neurite outgrowth. Neuron, 46:849-55.

Dubreuil CI, Winton MJ, McKerracher L. 2003. Rho activation patterns after spinal cord injury and the role of activated Rho in apoptosis in the central nervous system. $J$ Cell Biol, 162:233-43.

Eickholt BJ, Walsh FS, Doherty P. 2002. An inactive pool of GSK-3 at the leading edge of growth cones is implicated in Semaphorin 3A signaling. J Cell Biol, 157:211-7.

Eriksen JL, Sagi SA, Smith TE, et al. 2003. NSAIDs and enantiomers of flurbiprofen target gamma-secretase and lower Abeta 42 in vivo. J Clin Invest, 112:440-9. 
Fassbender K, Simons M, Bergmann C, et al. 2001. Simvastatin strongly reduces levels of Alzheimer's disease beta-amyloid peptides Abeta 42 and Abeta 40 in vitro and in vivo. Proc Natl Acad Sci USA, 98:5856-61.

Fischer D, Petkova V, Thanos S, et al. 2004. Switching mature retinal ganglion cells to a robust growth state in vivo: gene expression and synergy with RhoA inactivation. J Neurosci, 24:8726-40.

Fournier AE, GrandPre T, Strittmatter SM. 2001. Identification of a receptor mediating Nogo-66 inhibition of axonal regeneration. Nature, 409:341-6.

Fournier AE, Takizawa BT, Strittmatter SM. 2003. Rho kinase inhibition enhances axonal regeneration in the injured CNS. $J$ Neurosci, 23:1416-23.

Fukata M, Nakagawa M, Kaibuchi K. 2003. Roles of Rho-family GTPases in cell polarisation and directional migration. Curr Opin Cell Biol, 15:590-7.

Garcia JH, Yoshida Y, Chen H, et al. 1993. Progression from ischemic injury to infarct following middle cerebral artery occlusion in the rat. Am J Pathol, 142:623-35.

Galasko DR, Graff-Radford N, May S, et al. 2007. Safety, tolerability, pharmacokinetics, and Abeta levels after short-term administration of R-flurbiprofen in healthy elderly individuals. Alzheimer Dis Assoc Disord, 21:292-9.

Geerts H. 2007. Drug evaluation: (R)-flurbiprofen--an enantiomer of flurbiprofen for the treatment of Alzheimer's disease. IDrugs, 10:121-33.

GrandPre T, Li S, Strittmatter SM. 2002. Nogo-66 receptor antagonist peptide promotes axonal regeneration. Nature, 417:547-51.

Hara M, Takayasu M, Watanabe K, et al. 2000. Protein kinase inhibition by fasudil hydrochloride promotes neurological recovery after spinal cord injury in rats. J Neurosurg, 93: 94-101.

Hardy J, Selkoe DJ. 2002. The amyloid hypothesis of Alzheimer's disease: progress and problems on the road to therapeutics. Science, 297:353-6

Hasegawa Y, Fujitani M, Hata K, et al. 2004. Promotion of axon regeneration by myelin-associated glycoprotein and Nogo through divergent signals downstream of Gi/G. J Neurosci, 24:6826-32.

Hata K, Fujitani M, Yasuda Y, et al. 2006. RGMa inhibition promotes axonal growth and recovery after spinal cord injury. $J$ Cell Biol, 173: 47-58.

Ikebe M, Hartshorne DJ. 1985. Phosphorylation of smooth muscle myosin at two distinct sites by myosin light chain kinase. J Biol Chem, 260:10027-31.

Ikebe M, Hartshorne DJ, Elzinga M. 1986. Identification, phosphorylation, and dephosphorylation of a second site for myosin light chain kinase on the 20,000-dalton light chain of smooth muscle myosin. $J$ Biol Chem, 261:36-9.

Ishizaki T, Maekawa M, Fujisawa K, et al. 1996. The small GTP-binding protein Rho binds to and activates a $160 \mathrm{kDa} \mathrm{Ser} / \mathrm{Thr}$ protein kinase homologous to myotonic dystrophy kinase. EMBO J, 15:1885-93.

Ishizaki T, Uehata M, Tamechika I, et al. 2000. Pharmacological properties of Y-27632, a specific inhibitor of rho-associated kinases. Mol Pharmacol, 57:976-83.

Ito Y, Oinuma I, Katoh H, et al. 2006. Sema4D/plexin-B1 activates GSK3beta through R-Ras GAP activity, inducing growth cone collapse EMBO Rep, 7:704-9.

Jacobs M, Hayakawa K, Swenson L, et al. 2006. The structure of dimeric ROCK I reveals the mechanism for ligand selectivity. $J$ Biol Chem, 281:260-8.

Jick H, Zornberg GL, Jick SS, et al. 2000. Statins and the risk of dementia. Lancet, 356:1627-31.

Josephson A, Trifunovski A, Widmer HR, et al. 2002. Nogo-receptor gene activity: cellular localization and developmental regulation of mRNA in mice and humans. J Comp Neurol, 453:292-304.

Kim JE, Li S, GrandPre T, et al. 2003. Axon regeneration in young adult mice lacking Nogo-A/B. Neuron, 38:187-99.

Kim JE, Liu BP, Park JH, et al. 2004. Nogo-66 receptor prevents raphespinal and rubrospinal axon regeneration and limits functional recovery from spinal cord injury. Neuron, 44:439-51.
Kojro E, Gimpl G, Lammich S, et al. 2001. Low cholesterol stimulates the nonamyloidogenic pathway by its effect on the alpha -secretase ADAM 10. Proc Natl Acad Sci USA, 98:5815-20.

Koprivica V, Cho KS, Park JB et al. 2005. EGFR activation mediates inhibition of axon regeneration by myelin and chondroitin sulfate proteoglycans. Science, 310:106-10.

Kottis V, Thibault P, Mikol D, et al. 2002. Oligodendrocyte-myelin glycoprotein (OMgp) is an inhibitor of neurite outgrowth. $J$ Neurochem, 82:1566-9.

Kubo T, Hata K, Yamaguchi A et al. 2007. Rho-ROCK inhibitors as emerging strategies to promote nerve regeneration. Curr Pharm Des, 13:2493-9.

Kubo T, Endo M, Hata K et al. 2008. Myosin IIA is required for neurite outgrowth inhibition produced by repulsive guidance molecule. $J$ Neurochem, in press.

Kukar T, Murphy MP, Eriksen JL, et al. 2005. Diverse compounds mimic Alzheimer disease-causing mutations by augmenting Abeta 42 production. Nat Med, 11:545-50.

Kukar T, Prescott S, Eriksen JL, et al. 2007. Chronic administration of R-flurbiprofen attenuates learning impairments in transgenic amyloid precursor protein mice. BMC Neurosci, 8:54.

Laufs U, Endres M, Stagliano N, et al. 2000. Neuroprotection mediated by changes in the endothelial actin cytoskeleton. J Clin Invest, 106:15-24.

Lehmann M, Fournier A, Selles-Navarro I, et al. 1999. Inactivation of Rho signaling pathway promotes CNS axon regeneration. J Neurosci, 19:7537-47.

Lepley D, Paik JH, Hla T, et al. 2005. The G protein-coupled receptor S1P2 regulates Rho/Rho kinase pathway to inhibit tumor cell migration. Cancer Res, 65:3788-95.

Leuchtenberger S, Kummer MP, Kukar T, et al. 2006. Inhibitors of Rhokinase modulate amyloid-beta (Abeta) secretion but lack selectivity for Abeta42. J Neurochem, 96:355-65.

Leung T, Manser E, Tan L, et al. 1995. A novel serine/threonine kinase binding the Ras-related RhoA GTPase which translocates the kinase to peripheral membranes. J Biol Chem, 270:29051-4.

Li M, Shibata A, Li C, et al. 1996. Myelin-associated glycoprotein inhibits neurite/axon growth and causes growth cone collapse. J Neurosci Res, 46:404-14.

Li S, Strittmatter SM. 2003. Delayed systemic Nogo-66 receptor antagonist promotes recovery from spinal cord injury. J Neurosci, 23:4219-27.

Lingor P, Teusch N, Schwarz K, et al. 2007. Inhibition of Rho kinase (ROCK) increases neurite outgrowth on chondroitin sulphate proteoglycan in vitro and axonal regeneration in the adult optic nerve in vivo. J Neurochem, 103:181-9.

Madura T, Yamashita T, Kubo T, et al. 2004. Activation of Rho in the injured axons following spinal cord injury. EMBO Rep, 5:412-7.

Matsui T, Amano M, Yamamoto T, et al. 1996. Rho-associated kinase, a novel serine/threonine kinase, as a putative target for small GTP binding protein Rho. EMBO J, 15:2208-16.

McGeer PL, McGeer E, Rogers J et al. 1990. Anti-inflammatory drugs and Alzheimer disease. Lancet, 335:1037.

McGeer PL, Schulzer M, McGeer EG. 1996. Arthritis and anti-inflammatory agents as possible protective factors for Alzheimer's disease: a review of 17 epidemiologic studies. Neurology, 47:425-32.

McKerracher L, David S, Jackson DL, et al. 1994. Identification of myelinassociated glycoprotein as a major myelin-derived inhibitor of neurite growth. Neuron, 13:805-11.

McKerracher L, Higuchi H. 2006. Targeting Rho to stimulate repair after spinal cord injury. J Neurotrauma, 23:309-17.

Merkler D, Metz GA, Raineteau O, et al. 2001. Locomotor recovery in spinal cord-injured rats treated with an antibody neutralizing the myelinassociated neurite growth inhibitor Nogo-A. J Neurosci, 21:3665-73.

Mi S, Lee X, Shao Z, et al. 2004. LINGO-1 is a component of the NOGO-66 receptor/p75 signaling complex. Nat Neurosci, 7:221-8.

Mimura F, Yamagishi S, Arimura N, et al. 2006. MAG inhibits microtubule assembly by a Rho-kinase dependent mechanism. $J$ Biol Chem, 281:15970-9. 
Monnier PP, Sierra A, Schwab JM, et al. 2003. The Rho/ROCK pathway mediates neurite growth-inhibitory activity associated with the chondroitin sulfate proteoglycans of the CNS glial scar. Mol Cell Neurosci, 22:319-30.

Morihara T, Chu T, Ubeda O, et al. 2002. Selective inhibition of Abeta42 production by NSAID R-enantiomers. J Neurochem, 83:1009-12.

Mueller BK, Mack H, Teusch N. 2005. Rho kinase, a promising drug target for neurological disorders. Nat Rev Drug Discov, 4:387-98.

Mukhopadhyay G, Doherty P, Walsh FS, et al. 1994. Crocker PR, Filbin MT. A novel role for myelin-associated glycoprotein as an inhibitor of axonal regeneration. Neuron, 13:757-67.

Nagumo H, Sasaki Y, Ono Y, et al. 2000. Rho kinase inhibitor HA-1077 prevents Rho-mediated myosin phosphatase inhibition in smooth muscle cells. Am J Physiol Cell Physiol, 278:C57-65.

Nakagawa O, Fujisawa K, Ishizaki T, et al. 1996. ROCK-I and ROCK-II, two isoforms of Rho-associated coiled-coil forming protein serine/threonine kinase in mice. FEBS Lett, 392:189-93.

Nakajima E, Nakajima T, Minagawa Y, et al. 2005. Contribution of ROCK in contraction of trabecular meshwork: proposed mechanism for regulating aqueous outflow in monkey and human eyes. $J$ Pharm Sci, 94:701-8.

Narumiya S, Yasuda S. 2006. Rho GTPases in animal cell mitosis. Curr Opin Cell Biol, 18:199-205.

Nishikimi T, Matsuoka H. 2006. Molecular mechanisms and therapeutic strategies of chronic renal injury: renoprotective effect of rho-kinase inhibitor in hypertensive glomerulosclerosis. J Pharmacol Sci, 100:22-8.

Oertle T, van der Haar ME, Bandtlow CE, et al. 2003. Nogo-A inhibits neurite outgrowth and cell spreading with three discrete regions. J Neurosci, 23:5393-406.

Ohashi K, Nagata K, Maekawa M, et al. 2000. Rho-associated kinase ROCK activates LIM-kinase 1 by phosphorylation at threonine 508 within the activation loop. J Biol Chem, 275:3577-82.

Ostrowski SM, Wilkinson BL, Golde TE, et al. 2007. Statins reduce amyloid-beta production through inhibition of protein isoprenylation. $J$ Biol Chem, 282:26832-44.

Park JB, Yiu G, Kaneko S, et al. 2005. A TNF receptor family member, TROY, is a coreceptor with Nogo receptor in mediating the inhibitory activity of myelin inhibitors. Neuron, 45:345-51.

Parvathy S, Ehrlich M, Pedrini S, et al. 2004. Atorvastatin-induced activation of Alzheimer's alpha secretase is resistant to standard inhibitors of protein phosphorylation-regulated ectodomain shedding. J Neurochem, 90:1005-10.

Pedrini S, Carter TL, Prendergast G, et al. 2005. Modulation of statinactivated shedding of Alzheimer APP ectodomain by ROCK. PLoS Med, 2:e18.

Petanceska SS, DeRosa S, Olm V, et al. 2002. Statin therapy for Alzheimer's disease: will it work? J Mol Neurosci, 19:155-61.

Petratos S, Li QX, George AJ, et al. 2008. The -amyloid protein of Alzheimer's disease increases neuronal CRMP-2 phosphorylation by a Rho-GTP mechanism. Brain, 131:90-108.

Rajagopalan S, Deitinghoff L, Davis D, et al. 2004. Neogenin mediates the action of repulsive guidance molecule. Nat Cell Biol, 6:756-62.

Richardson PM, McGuinness UM, Aguayo AJ. 1980. Axons from CNS neurons regenerate into PNS grafts. Nature, 284:264-5.

Riento K, Ridley AJ. 2003. Rocks: multifunctional kinases in cell behaviour. Nat Rev Mol Cell Biol, 4:446-56.

Rikitake Y, Kim HH, Huang Z, et al. 2005. Inhibition of Rho kinase (ROCK) leads to increased cerebral blood flow and stroke protection. Stroke, 36:2251-7.

Rockwood K, Kirkland S, Hogan DB, et al. 2002. Use of lipid-lowering agents, indication bias, and the risk of dementia in community-dwelling elderly people. Arch Neurol, 59:223-7.

Sagawa H, Terasaki H, Nakamura M, et al. 2007 A novel ROCK inhibitor, Y-39983, promotes regeneration of crushed axons of retinal ganglion cells into the optic nerve of adult cats. Exp Neurol, 205:230-40.
Sagi SA, Weggen S, Eriksen J et al. 2003. The non-cyclooxygenase targets of non-steroidal anti-inflammatory drugs, lipoxygenases, peroxisome proliferator-activated receptor, inhibitor of kappa B kinase, and NF kappa B, do not reduce amyloid beta 42 production. J Biol Chem, 278:31825-30.

Saitoh A, Yamada M, Yamada M, et al. 2006. ROCK inhibition produces anxiety-related behaviors in mice. Psychopharmacology (Berl), 188:1-11.

Sasaki Y, Suzuki M, Hidaka H. 2002. The novel and specific Rho-kinase inhibitor (S)-(+)-2-methyl-1-[(4-methyl-5-isoquinoline)sulfonyl]homopiperazine as a probing molecule for Rho-kinase-involved pathway. Pharmacol Ther, 93:225-32.

Satoh S, Utsunomiya T, Tsurui K, et al. 2001. Pharmacological profile of hydroxy fasudil as a selective rho kinase inhibitor on ischemic brain damage. Life Sci, 69:1441-53.

Satoh S, Toshima Y, Ikegaki I, et al. 2007. Wide therapeutic time window for fasudil neuroprotection against ischemia-induced delayed neuronal death in gerbils. Brain Res, 1128:175-80.

Schnell L, Schwab ME. 1990. Axonal regeneration in the rat spinal cord produced by an antibody against myelin-associated neurite growth inhibitors. Nature, 343:269-72.

Sebbagh M, Hamelin J, Bertoglio J, et al. 2005. Direct cleavage of ROCK II by granzyme B induces target cell membrane blebbing in a caspaseindependent manner. $J$ Exp Med, 201:465-71.

Sebbagh M, Renvoize C, Hamelin J, et al. 2001. Caspase-3-mediated cleavage of ROCK I induces MLC phosphorylation and apoptotic membrane blebbing. Nat Cell Biol, 3:346-52.

Shamah SM, Lin MZ, Goldberg JL, et al. 2001. EphA receptors regulate growth cone dynamics through the novel guanine nucleotide exchange factor ephexin. Cell, 105:233-44.

Shao Z, Browning JL, Lee X, et al. 2005. TAJ/TROY, an orphan TNF receptor family member, binds Nogo-66 receptor 1 and regulates axonal regeneration. Neuron, 45:353-9.

Shibuya M, Hirai S, Seto M, et al. 2005. Effects of fasudil in acute ischemic stroke: results of a prospective placebo-controlled double-blind trial. $J$ Neurol Sci, 238:31-9.

Shibuya M, Suzuki Y, Sugita K, et al. 1992. Effect of AT877 on cerebral vasospasm after aneurismal subarachnoid hemorrhage. Results of a prospective placebo-controlled double-blind trial. J Neurosurg, 76:571-7.

Shimizu Y, Thumkeo D, Keel J, et al. 2005. ROCK-I regulates closure of the eyelids and ventral body wall by inducing assembly of actomyosin bundles. J Cell Biol, 168:941-53.

Shimokawa H. 2002. Rho-kinase as a novel therapeutic target in treatment of cardiovascular diseases. J Cardiovasc Pharmacol, $39: 319-27$.

Shimokawa H , Hiramori K, Iinuma H, et al. 2002. Anti-anginal effect of fasudil, a Rho-kinase inhibitor, in patients with stable effort angina: a multicenter study. J Cardiovasc Pharmacol, 40:751-61.

Shimokawa H, Rashid M. 2007. Development of Rho-kinase inhibitors for cardiovascular medicine. Trends Pharmacol Sci, 28:296-302.

Simonen M, Pedersen V, Weinmann O, et al. 2003. Systemic deletion of the myelin-associated outgrowth inhibitor Nogo-A improves regenerative and plastic responses after spinal cord injury. Neuron, 38:201-11.

Sivasankaran R, Pei J, Wang KC, et al. 2004. PKC mediates inhibitory effects of myelin and chondroitin sulfate proteoglycans on axonal regeneration. Nat Neurosci, 7:261-8.

Song XY, Zhong JH, Wang X, et al. 2004. Suppression of p75NTR does not promote regeneration of injured spinal cord in mice. $J$ Neurosci, 14:542-6.

Sumi T, Matsumoto K, Nakamura T. 2001. Specific activation of LIM kinase 2 via phosphorylation of threonine 505 by ROCK, a Rho-dependent protein kinase. J Biol Chem, 276:670-6.

Sung JK, Miao L, Calvert JW, et al. 2003. A possible role of RhoA/ Rho-kinase in experimental spinal cord injury in rat. Brain Res, 959:29-38. 
Swiercz JM, Kuner R, Behrens J, et al. 2002. Plexin-B1 directly interacts with PDZ-RhoGEF/LARG to regulate RhoA and growth cone morphology. Neuron, 35:51-63.

Takahashi Y, Hayashi I, Tominari Y, et al. 2003. Sulindac sulfide is a noncompetitive gamma-secretase inhibitor that preferentially reduces Abeta 42 generation. $J$ Biol Chem, 278:18664-70.

Tamura M, Nakao H, Yoshizaki H, et al. 2005. Development of specific Rho-kinase inhibitors and their clinical application. Biochim Biophys Acta, 1754:245-52.

Tanaka H, Yamashita T, Yachi K, et al. 2004. Cytoplasmic p21(Cip1/WAF1) enhances axonal regeneration and functional recovery after spinal cord injury in rats. Neuroscience, 127:155-64.

Thumkeo D, Keel J, Ishizaki T, et al. 2003. Targeted disruption of the mouse rho-associated kinase 2 gene results in intrauterine growth retardation and fetal death. Mol Cell Biol, 23:5043-55.

Tokushige H, Inatani M, Nemoto S, et al. 2007. Effects of topical administration of y-39983, a selective rho-associated protein kinase inhibitor, on ocular tissues in rabbits and monkeys. Invest Ophthalmol Vis Sci, 48:3216-22.

Toshima Y, Satoh S, Ikegaki I, et al. 2000. A new model of cerebral microthrombosis in rats and the neuroprotective effect of a Rho-kinase inhibitor. Stroke, 31:2245-50.

Uehata M, Ishizaki T, Satoh H, et al. 1997. Calcium sensitization of smooth muscle mediated by a Rho-associated protein kinase in hypertension. Nature, 389:990-4.

Venkitaramani DV, Chin J, Netzer WJ, et al. 2007. Beta-amyloid modulation of synaptic transmission and plasticity. $J$ Neurosci, 27:11832-7.

Vicari RM, Chaitman B, Keefe D, et al. 2005. Efficacy and safety of fasudil in patients with stable angina: a double-blind, placebo-controlled, phase 2 trial. J Am Coll Cardiol, 46:1803-11.

Wahl S, Barth H, Ciossek T, et al. 2000. Ephrin-A5 induces collapse of growth cones by activating Rho and Rho kinase. J Cell Biol, 149:263-70.

Walsh DM, Selkoe DJ. 2004. Deciphering the molecular basis of memory failure in Alzheimer's disease. Neuron, 44:181-93.

Wang KC, Kim JA, Sivasankaran R, et al. 2002a. p75 interacts with the Nogo receptor as a co-receptor for Nogo, MAG and OMgp. Nature, 420:74-8.

Wang KC, Koprivica V, Kim JA, et al. 2002b. Oligodendrocyte-myelin glycoprotein is a Nogo receptor ligand that inhibits neurite outgrowth. Nature, 417:941-4.

Wang X, Chun SJ, Treloar H, et al. 2002c. Localization of Nogo-A and Nogo-66 receptor proteins at sites of axon-myelin and synaptic contact. J Neurosci, 22:5505-15.

Weggen S, Eriksen JL, Das P, et al. 2001. A subset of NSAIDs lower amyloidogenic Abeta42 independently of cyclooxygenase activity. Nature, 414:212-6.
Weggen S, Eriksen JL, Sagi SA, et al. 2003. Evidence that nonsteroidal anti-inflammatory drugs decrease amyloid beta 42 production by direct modulation of gamma-secretase activity. J Biol Chem, 278:31831-7.

Wei L, Roberts W, Wang L, et al. 2001. Rho kinases play an obligatory role in vertebrate embryonic organogenesis. Development, 128:2953-62.

Wolozin B, Kellman W, Ruosseau P et al. 2000. Decreased prevalence of Alzheimer disease associated with 3-hydroxy-3-methyglutaryl coenzyme A reductase inhibitors. Arch Neurol, 57:1439-43.

Wong ST, Henley JR, Kanning KC, et al. 2002. A p75 (NTR) and Nogo receptor complex mediates repulsive signaling by myelin-associated glycoprotein. Nat Neurosci, 5:1302-8.

Yaffe K, Barrett-Connor E, Lin F, et al. 2002. Serum lipoprotein levels, statin use, and cognitive function in older women. Arch Neurol, 59:378-84.

Yamaguchi H, Kasa M, Amano M, et al. 2006a. Molecular mechanism for the regulation of rho-kinase by dimerization and its inhibition by fasudil. Structure, 14:589-600.

Yamaguchi H, Miwa Y, Kasa M, et al. 2006b. Structural basis for induced-fit binding of Rho-kinase to the inhibitor Y-27632. J Biochem (Tokyo), 140:305-11.

Yamashita K, Kotani Y, Nakajima Y et al. 2007a. Fasudil, a Rho kinase (ROCK) inhibitor, protects against ischemic neuronal damage in vitro and in vivo by acting directly on neurons. Brain Res, 1154:215-24.

Yamashita T, Fujitani M, Yamagishi S, et al. 2005. Multiple signals regulate axon regeneration through the Nogo receptor complex. Mol Neurobiol, 32:105-11.

Yamashita T, Higuchi H, Tohyama M. 2002. The p75 receptor transduces the signal from myelin-associated glycoprotein to Rho. J Cell Biol, 157:565-70.

Yamashita T, Mueller BK, Hata K. 2007b. Neogenin and repulsive guidance molecule signaling in the central nervous system. Curr Opin Neurobiol, 17:29-34.

Yamashita T, Tohyama M. 2003. The p75 receptor acts as a displacement factor that releases Rho from Rho-GDI. Nat Neurosci, 6:461-7.

Zheng B, Atwal J, Ho C, et al. 2005. Genetic deletion of the Nogo receptor does not reduce neurite inhibition in vitro or promote corticospinal tract regeneration in vivo. Proc Natl Acad Sci USA, 102:1205-10.

Zheng B, Ho C, Li S, et al. 2003. Lack of enhanced spinal regeneration in Nogo-deficient mice. Neuron, 38:213-24.

Zhou Y, Su Y, Li B, et al. 2003. Nonsteroidal anti-inflammatory drugs can lower amyloidogenic Abeta42 by inhibiting Rho. Science, $302: 1215-7$. 
